\title{
History of Hawaiian Pomology: Introduction to the Workshop
}

\author{
Jules Janick ${ }^{1}$ \\ Department of Horticulture and Landscape Architecture, Purdue University, West Lafayette, IN 47907
}

The Hawaiian Islands were colonized by waves of Polynesian settlers perhaps as early as $300 \mathrm{CE}$. Fruit culture at that time was based on banana, breadfruit, candlenut, coconut, mountain apple, and pandanus. The first documented contact with Europe was the encounter of Hawaii by British explorer James Cook in 1778. Subsequent settlement by European and American planters brought in numerous fruit crops, including avocado, citrus, coffee, macadamia, mango, papaya, passionfruit, and pineapple, with varying success. The present workshop, History of Hawaiian Pomology, sponsored by the History of Horticultural Science and Pomology Working Groups, explored three famous fruit and nut crops of Hawaii: pineapple (oral presentation by Johnny Lopez), papaya (oral presentation by Richard Manshardt), and macadamia (oral presentation by David Rietow), each with very different stories and outcomes.

The first paper, entitled "Pineapple: The Rise and Fall of an Industry" by Duane P. Bartholomew, Richard A. Hawkins, and Johnny Lopez, reviews the Hawaiian history of one of the world's most famous tropical fruits. The industry was based on processing and export and reached its peak in terms of production in 1972. The spectacular ascent and precipitous decline of the pineapple area in Hawaii underscores the fact that horticulture is more than a science and an art but is an industry whose success depends on many factors, including climate and biotic factors but principally economics. As a result of labor costs, and foreign competition initiated by Hawaii-based companies (!), the Hawaiian pineapple industry that once covered almost 74,000 acres $(30,000$ ha) declined precipitously and essentially disappeared. However, breeding advances carried out in Hawaii by the Pineapple Research Institute culminating in the development of the 'MD-2' clone (Fig. 1) have led to a world resurgence in fresh pineapple but the impact has proved to be greatest outside of the islands.

The presentation "Papaya in Hawaii" by Richard Manshardt reviews the origins of one

\footnotetext{
Received for publication 13 June 2012. Accepted for publication 3 July 2012.

This paper was part of the workshop "History of Hawaiian Pomology" held 25 Sept. 2011 at the ASHS Conference, Waikoloa, HI, and sponsored by the History of Horticultural Science (HIST) and Pomology (POM) Working Groups.

${ }^{1}$ To whom reprint requests should be addressed; e-mail janick@purdue.edu.
}

of the great success stories of Hawaiian horticulture, a drama that continues to unfold. Papaya was introduced to the islands $\approx 1820$ and initially considered an inauspicious crop.
Since the early 20th century, breeding and the development of cultural techniques have been the backbone of the industry as demonstrated by the successful development and

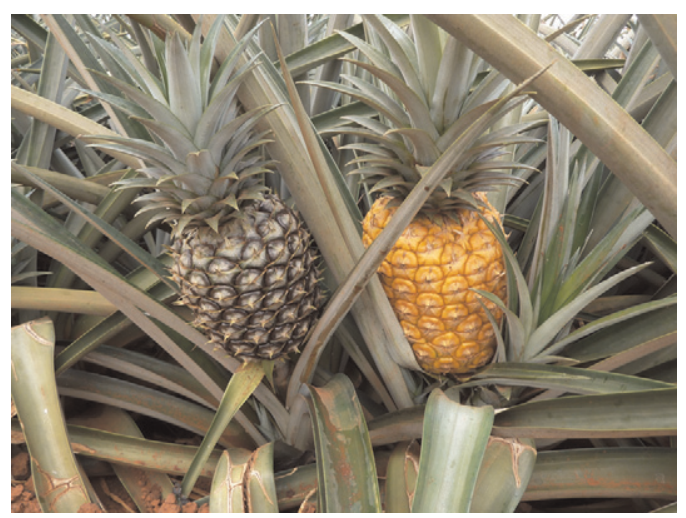

Fig. 1. The famous 'MD-2' pineapple developed in Hawaii at the Pineapple Research Institute has revitalized the world market for fresh pineapple.

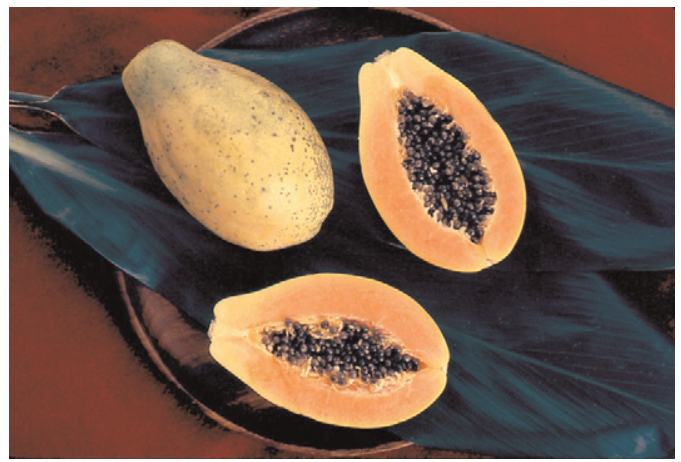

Fig. 2. The transgenic 'SunUp' papaya developed in Hawaii with resistance to the papaya ringspot virus has resurrected the Hawaiian papaya industry.

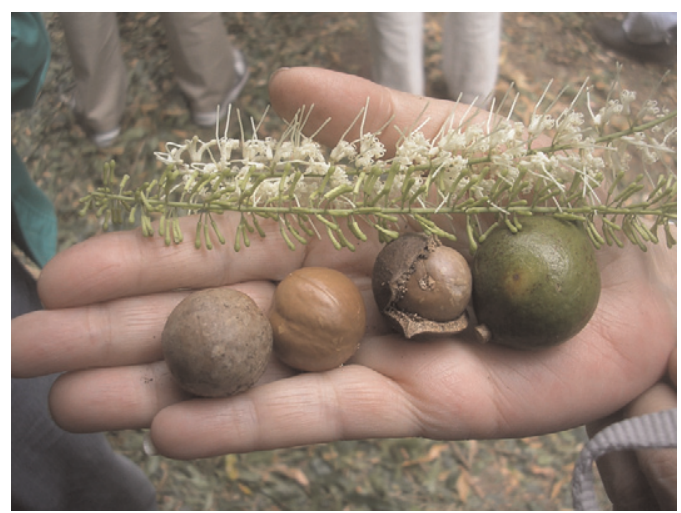

Fig. 3. Flowers and fruit of macadamia. 
production of the high-quality solo papaya types. However, from the 1950s, the papaya ringspot virus threatened to destroy the industry and nearly wiped it out. Salvation came as a result of developments in molecular biology carried out by collaborating researches at Cornell University, the University of Hawaii, and the USDA Sugarcane Research Laboratory. The incorporation of transgenic resistance in two cultivars, SunUp (Fig. 2) and Rainbow, has enabled the resurrection of the industry in Hawaii and elsewhere. Although the industry continues to struggle as a result of competition from Central and South America, acceptance of transgenic papaya in Asia is expected to revive the industry.

The last presentation by David Rietow, entitled "Macadamia: A Hard Nut to Crack," chronicles the development of an industry by Hawaiian pomologists from importation of a little known Australian species to its development and commercialization. The macadamia tree produces a nut with an extremely hard shell with a deliciously flavored kernel high in lipid content (Fig. 3). It is fair to say that the macadamia world industry is an innovation that owes its success to research and development carried out in Hawaii. However, the success of the Hawaiian macadamia industry has led to an expanding world production that has provided challenges to Hawaiian growers who are now battling to survive. 